\title{
An Indoor Radon Survey in Three Different Climate Regions in Mexico, and the Influence of Climate in the Obtained Values
}

\author{
Guillermo Espinosa ${ }^{1}$, Richard Gammage ${ }^{2}$ \\ ${ }^{1}$ Instituto de Física, Universidad Nacional Autónoma de México, Coyoacán, México; ${ }^{2}$ Oak Ridge National Laboratory, Oak Ridge, \\ USA. \\ Email: espinosa@fisica.unam.mx
}

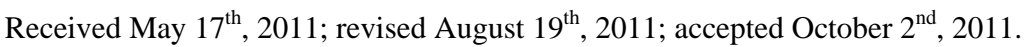

\begin{abstract}
In this paper we present the results of a survey of indoor radon concentration levels in Mexico. In order to investigate whether differences in climate translate into significant differences in indoor radon concentrations, the country was divided into three climate regions: the northern semi-desert region, the central semitropical region and the southern tropical region. The survey was carried out using nuclear track methodology. The dosimeters employed for the survey were based on the passive closed-end cup device, developed at the Physics Institute of the National Autonomous University of Mexico, and used PADC as detector material. A well-established protocol for chemically etching and reading the detectors was followed. Average annual temperatures differ between regions (from $15^{\circ} \mathrm{C}$ to $28^{\circ} \mathrm{C}$ ) but vary relatively little within each region. Atmospheric temperature is one of the most important factors which need to be considered when carrying out a survey of indoor radon concentrations because temperature largely determines building ventilation habits, and ventilation habits are known to have significant effects on indoor radon concentrations. Other factors, including building construction materials, architectural styles, geological and hydrological characteristics, and seismicity, vary from region to region and within each region. In each of the three regions low levels of indoor radon (from 37 to $179 \mathrm{~Bq} \cdot \mathrm{m}^{-3}$ ) were found.
\end{abstract}

Keywords: Radon, Indoor Radon, Climate Influence, Nuclear Tracks Methodology

\section{Introduction}

The radioactive gas radon is a decay product of naturally occurring uranium. Radon builds up in confined areas, and accounts for approximately $50 \%$ of the effective dose to which the general public is exposed [1]. The inhalation of radon progeny such as polonium, lead and bismuth is a significant cause of lung cancer throughout the world. Determining indoor radon concentrations in dwellings and workplaces is thus an important public health problem.

Several national and international organizations and institutions have conducted national surveys of indoor radon concentrations [2-5]. The measurement of indoor radon concentration levels forms a mandatory part of radiation safety procedures in the United Kingdom, the United States of America, the Nordic countries and, in general, countries which experience cold climates for a significant part of year.
The concentrations of radon and its progeny inside a given dwelling depend on numerous factors, the most important of which are the uranium concentrations both in the soil surrounding the dwelling and in the building materials themselves, atmospheric conditions, architectural style (for example, whether there is a slab basement, a crawl space, etc.), porosity of the surrounding soil, building layout, and the ventilation habits of the inhabitants of the building. The large variability in the factors listed above contribute to potentially large variability in indoor radon concentrations and motivate detailed, nation-wide indoor radon surveys such as that described here.

Indoor radon concentration measurements are also important from the public health point of view in countries with more benign climates. In these countries, the ventilation habits of the inhabitants, themselves largely determined by climate, are more important than other 
factors in determining the differences in the indoor radon levels over large spatial scales.

\subsection{Regulations and Action Levels in Selected Countries}

A radon action level is a concentration of radon gas above which remedial or protective actions should be carried out. Both the International Commission on Radiological Protection (ICRP) and the International Atomic Energy Agency (IAEA) suggest allowable radon concentrations of 200 to $600 \mathrm{~Bq} \cdot \mathrm{m}^{-3}$ in dwellings and 500 to $1500 \mathrm{~Bq} \cdot \mathrm{m}^{-3}$ in workplaces [6,7]. However both agencies allow national authorities a significant degree of autonomy in establishing action levels.

The European Union accepts the reference values recommended by the ICRP in its Publication 65 [7]. The United States Environmental Protection Agency (USEPA) uses a reference level of $148 \mathrm{~Bq} \cdot \mathrm{m}^{-3}$ for dwellings and $400 \mathrm{~Bq} \cdot \mathrm{m}^{-3}$ for workplaces [3]. In the UK, the Health and Safety Executive (HSE) [8] has adopted radon action levels of $200 \mathrm{~Bq} \cdot \mathrm{m}^{-3}$ for dwellings and $400 \mathrm{~Bq} \cdot \mathrm{m}^{-3}$ for workplaces. In Israel there is a mandatory reference level of $200 \mathrm{~Bq} \cdot \mathrm{m}^{-3}$ for already existing schools and day care centers and an advisory reference level of $400 \mathrm{~Bq} \cdot \mathrm{m}^{-3}$ for all other already existing workplaces. For new schools and day care centers the advisory level is $40 \mathrm{~Bq} \cdot \mathrm{m}^{-3}$ while that for other new workplaces [9]. In contrast, in Mexico there are no specific regulations relating to indoor radon levels in either homes or workplaces. It is hoped that the survey described here will aid the relevant government institutions to establish appropriate regulations in the near future.

\subsection{Indoor Radon Survey Strategy}

Mexico is a large country in terms of both area and population. It covers an area of 1,967,183 $\mathrm{km}^{2}$ and extends from the southern border of the United States, in North America, to the northern border of Guatemala, considered to be part of Central America. For the purposes of this study, the country was divided into three climatebased regions: the northern semi-desert region (region I), the central semi-tropical region (region II) and the southern tropical region (region III).

The northern semi-desert region I comprises the following ten states: Baja California, Chihuahua, Coahuila, Sonora, Nuevo Leon, Tamaulipas, Sinaloa, Durango, Zacatecas and San Luis Potosi. The Tropic of Cancer passes through the last seven of these states. Mean annual temperatures in these states vary between $13.5^{\circ} \mathrm{C}$ and $25.2^{\circ} \mathrm{C}$ and yearly rainfalls vary between 244 and 1305 $\mathrm{mm}$. The semi-tropical central region II comprises the Federal District and the states Aguascalientes, Nayarit,
Jalisco, Colima, Guanajuato, Michoacan, Queretaro, Hidalgo, Tlaxcala, Puebla and the State of Mexico. Average yearly temperatures in this region vary from $14.7^{\circ} \mathrm{C}$ to $24.8^{\circ} \mathrm{C}$ while mean annual rainfalls vary from 387 to $1349 \mathrm{~mm}$. Finally, the southern region, which comprises the states of Morelos, Guerrero, Veracruz, Oaxaca, Tabasco, Chiapas, Campeche, Yucatan and Quintana Roo, presents a tropical climate with average temperatures from $20.6^{\circ} \mathrm{C}$ to $26.8^{\circ} \mathrm{C}$ and rainfalls from 645 to 2050 $\mathrm{mm}$. The three regions are shown in Figure 1.

The indoor radon survey described here was carried out over a one-year period. The measurement period was divided into four three-month periods, corresponding to the (northern hemisphere) fall and winter of 2008 and the spring and summer of 2009. These periods were chosen to coincide as closely as possible with those of the previous national indoor radon survey carried out ten years earlier [10].

\subsection{Number and Location of Dwellings and Detectors}

Dwellings in the three most populated cities of each state in the country were chosen for the indoor radon level survey. This ensured the inclusion of each state capital in the survey. An exception to the three-city rule was the Federal District (Distrito Federal) in region II, which is almost entirely occupied by Mexico City.

Houses of approximately the same age, regardless of architectural style, and where permission had been given by the owner and/or occupants, were chosen randomly for the survey. The measurements were taken in the liv-

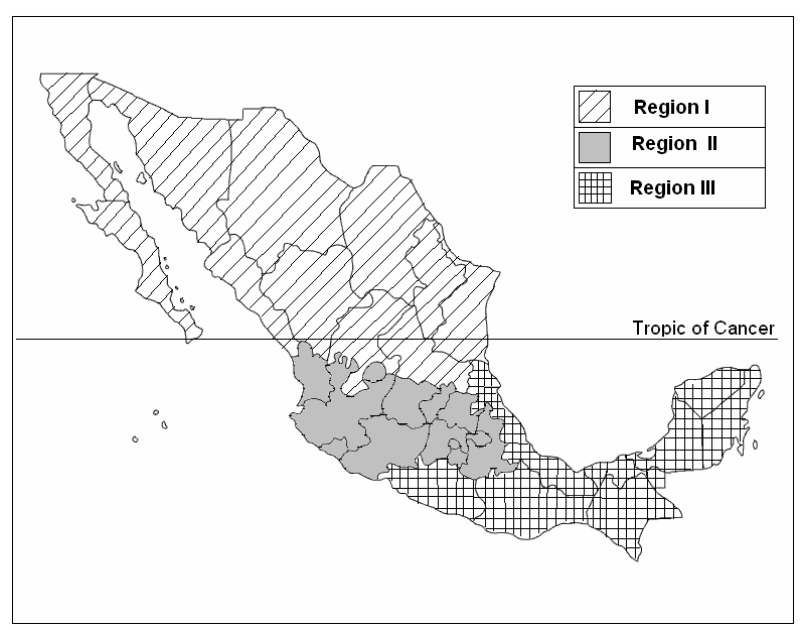

Figure 1. Mexico was divided into three climate-based regions for the purposes of the indoor radon survey: the northern semi-desert region (region I), the central semi-tropical region (region II) and the southern tropical region (region III). 
ing rooms, and two detectors were placed at each location. A total number of 3167 dwellings (approximately 100 in each state) were used in the survey.

\section{Method}

The indoor radon survey was carried out using nuclear track methodology. The dosimeters used for the survey were based on the passive closed-end cup device, developed at the Physics Institute of the National Autonomous University of Mexico (UNAM), with poly allyl diglycol carbonate (PADC) as detector material [11].

The detectors were prepared and the tracks read following a well-established protocol. Before exposure the detectors were chemically pre-etched in order to eliminate surface impurities, scratches and irregularities, washed in distilled water and dried. After exposure the tracks were developed using a one-step chemical etch in a $6.25 \mathrm{M} \mathrm{KOH}$ solution at $60 \pm 1^{\circ} \mathrm{C}$ for 18 hours. The detectors were then washed in running dis- tilled water and dried in desiccant paper. This process is well established and highly reliable [12].

The tracks were counted automatically by a Digital Image Analysis System (DIAS) [13] and the data automatically analyzed using a PC with Microsoft Excel software. The detection device was calibrated using the Oak Ridge National Laboratory radon chamber [10]. The process was verified using the chamber at the Physics Institute of the UNAM every three months, or whenever new CR-39 material arrived from the producer.

\subsection{Detect to Protect}

Differences in recommended indoor radon action levels are due both to spatial differences in uranium concentrations and to the cost of mitigation procedures. There is only way to manage the problem of indoor radon: to "Detect to Protect" [14]. This philosophy underlines the importance of measuring indoor radon levels, particularly in dwellings and workplaces, by reminding us that appropriate mitigation or protection measures are only able to be determined and taken if indoor radon levels have first been measured.

\subsection{Dose Calculation Method}

The effective dose and the derived risks are associated mainly with the inhalation of short-lived polonium $\left({ }^{218} \mathrm{Po}\right.$ and ${ }^{214} \mathrm{Po}$ ), a radon progeny alpha emitter. A comprehensive analysis of the radiation dose should consider detailed information on this aerosol as well as the degree of disequilibrium between radon and its progeny for each site and for each season. The literature reports values of the equilibrium factor ranging between 0.36 and 0.52 , which suggests that an average value of 0.4 could be acceptable in order to estimate exposure to radon progeny from radon concentration measurements [1].

\section{Results}

Table 1 shows the geological characteristics, basic environmental factors, architecture style and seismicity, and ventilation methods most commonly found in each of the three regions of the survey.

Table 2 lists the states in each region, the number of dwellings monitored in each state, the minimum, maximum and mean radon concentration in each state, the standard deviation of the radon concentration in each state, the total number of dwellings monitored in each region, and the mean radon concentration in each region. The most important observation is that no state average

Table 1. The geological characteristics, basic environmental factors, architecture style and seismicity, and ventilation methods most commonly found in each of the three regions.

\begin{tabular}{|c|c|c|c|}
\hline & Region I & Region II & Region III \\
\hline Climate classification & Semi-desert & Semi-tropical & Tropical \\
\hline Soil characteristics & $\begin{array}{l}\text { Lithosols, regosols, aridisols, } \\
\text { sierozem, desertic soils }\end{array}$ & $\begin{array}{l}\text { Lithosols, regosols, volcanic } \\
\text { ashes, vertisols, lateritic oxisols }\end{array}$ & $\begin{array}{l}\text { Lithosols, regosols, alluvial soils, } \\
\text { rendzinas, gleysols, savanna soils }\end{array}$ \\
\hline Hydrological characteristics & Groundwater, no river or lakes & Rivers and some small lakes & Important river systems and lakes \\
\hline Building materials & Clay brick, stone and concrete & $\begin{array}{l}\text { Clay brick, stone, gypsum and } \\
\text { concrete }\end{array}$ & Adobe, wood and palm leaf roofs \\
\hline Architecture & Rustic, without basements & $\begin{array}{l}\text { Colonial and semi-rustic, without } \\
\text { basements }\end{array}$ & $\begin{array}{l}\text { Traditional and rustic without } \\
\text { basements }\end{array}$ \\
\hline Ventilation & Non air-conditioned, open windows & $\begin{array}{l}\text { Non air-conditioned, open } \\
\text { windows }\end{array}$ & $\begin{array}{l}\text { Non air-conditioned, open } \\
\text { windows and doors }\end{array}$ \\
\hline Mean annual rainfall & $492 \mathrm{~mm}$ & $762 \mathrm{~mm}$ & $1080 \mathrm{~mm}$ \\
\hline Mean annual temperature & $20.7^{\circ} \mathrm{C}$ & $17.6^{\circ} \mathrm{C}$ & $24.7^{\circ} \mathrm{C}$ \\
\hline
\end{tabular}


Table 2. The states in each region, the number of dwellings in each state, the minimum, maximum and mean radon concentration, and the standard deviation of the radon concentration, in each state, the number of dwellings in each region, and the mean radon concentration in each region.

\begin{tabular}{|c|c|c|c|c|c|c|}
\hline $\begin{array}{c}\text { Region } \\
\text { REGION I }\end{array}$ & State & $\begin{array}{l}\text { Number of dwellings } \\
\text { monitored }\end{array}$ & $\operatorname{Min}\left(\mathrm{Bq} \cdot \mathrm{m}^{-3}\right)$ & $\operatorname{Max}\left(\mathrm{Bq} \cdot \mathrm{m}^{-3}\right)$ & Mean $\left(\mathrm{Bq} \cdot \mathrm{m}^{-3}\right)$ & $\begin{array}{c}\text { Std. } \\
\text { Deviation }(\sigma)\end{array}$ \\
\hline 1 & Baja California & 90 & 77 & 120 & 88 & 7.52 \\
\hline 2 & Baja California Sur & 90 & 50 & 90 & 70 & 5.10 \\
\hline 3 & Sonora & 90 & 70 & 92 & 74 & 5.93 \\
\hline 4 & Chihuahua & 95 & 85 & 179 & 130 & 7.83 \\
\hline 5 & Coahuila & 90 & 72 & 110 & 98 & 5.86 \\
\hline 6 & Nuevo León & 100 & 77 & 118 & 97 & 7.64 \\
\hline 7 & Tamaulipas & 90 & 66 & 93 & 81 & 7.52 \\
\hline 8 & Sinaloa & 95 & 48 & 87 & 77 & 6.31 \\
\hline 9 & Durango & 95 & 51 & 92 & 82 & 5.91 \\
\hline 10 & Zacatecas & 100 & 82 & 122 & 110 & 7.73 \\
\hline \multirow[t]{2}{*}{11} & San Luis Potosí & 100 & 67 & 100 & 88 & 7.21 \\
\hline & Total & 1035 & & Average & 90.5 & 6.78 \\
\hline REGION II & State & $\begin{array}{c}\text { Number of dwellings } \\
\text { monitored }\end{array}$ & $\underset{\left(\mathrm{Bq} \cdot \mathrm{m}^{-3}\right)}{\operatorname{Min}}$ & $\begin{array}{c}\mathrm{Max} \\
\left(\mathrm{Bq} \cdot \mathrm{m}^{-3}\right)\end{array}$ & $\begin{array}{l}\text { Mean } \\
\left(\mathrm{Bq} \cdot \mathrm{m}^{-3}\right)\end{array}$ & $\begin{array}{c}\text { Std. } \\
\text { Deviation }(\sigma)\end{array}$ \\
\hline 12 & Aguascalientes & 90 & 77 & 115 & 101 & 7.33 \\
\hline 13 & Nayarit & 90 & 48 & 80 & 75 & 6.25 \\
\hline 14 & Jalisco & 90 & 57 & 110 & 97 & 7.56 \\
\hline 15 & Colima & 80 & 47 & 74 & 69 & 7.12 \\
\hline 16 & Guanajuato & 100 & 63 & 112 & 99 & 7.81 \\
\hline 17 & Michoacan & 100 & 76 & 124 & 80 & 7.60 \\
\hline 18 & Queretaro & 100 & 77 & 120 & 110 & 7.42 \\
\hline 19 & Hidalgo & 80 & 67 & 109 & 97 & 6.93 \\
\hline 20 & Tlaxcala & 80 & 72 & 97 & 87 & 6.91 \\
\hline 21 & Puebla & 100 & 99 & 135 & 115 & 7.45 \\
\hline 22 & Estado de México & $200 * *$ & 57 & 103 & 87 & 5.91 \\
\hline \multirow[t]{2}{*}{23} & Distrito Federal & $200 * *$ & 59 & 130 & 85 & 6.12 \\
\hline & Total & 1310 & & Average & 91.8 & 7.03 \\
\hline REGION III & State & $\begin{array}{c}\text { Number of dwellings } \\
\text { monitored }\end{array}$ & $\underset{\left(\mathrm{Bq} \cdot \mathrm{m}^{-3}\right)}{\operatorname{Min}}$ & $\begin{array}{c}\operatorname{Max} \\
\left(\mathrm{Bq} \cdot \mathrm{m}^{-3}\right)\end{array}$ & $\begin{array}{l}\text { Mean } \\
\left(\mathrm{Bq} \cdot \mathrm{m}^{-3}\right)\end{array}$ & $\begin{array}{c}\text { Std. } \\
\text { Deviation }(\sigma)\end{array}$ \\
\hline 24 & Morelos & 93 & 48 & 103 & 74 & 6.23 \\
\hline 25 & Guerrero & 89 & 45 & 97 & 70 & 7.12 \\
\hline 26 & Veracruz & 95 & 42 & 78 & 65 & 6.05 \\
\hline 27 & Oaxaca & 90 & 55 & 101 & 87 & 7.16 \\
\hline 28 & Tabasco & 90 & 41 & 87 & 62 & 5.82 \\
\hline 29 & Chiapas & 90 & 43 & 86 & 58 & 5.40 \\
\hline 30 & Campeche & 90 & 41 & 79 & 55 & 5.50 \\
\hline 31 & Yucatan & 95 & 37 & 81 & 51 & 5.37 \\
\hline \multirow[t]{2}{*}{32} & Quintana Roo & 90 & 48 & 77 & 69 & 5.51 \\
\hline & Total & 822 & & Average & 65.7 & 6.02 \\
\hline
\end{tabular}

** Densely-populated locations. 
indoor radon concentration, and hence no regional average concentration, is above the USEPA recommended action level of $148 \mathrm{~Bq} \cdot \mathrm{m}^{-3}$. These measured values are surprising, being lower than the average in door radon concentrations measured in other countries by other surveys $[2,15,16]$.

The frequency distribution of state average radon concentrations is shown in Figure 2. It can be seen that most states have mean indoor radon concentrations of between 60 and $100 \mathrm{~Bq} \cdot \mathrm{m}^{-3}$.

\section{Dose Calculation Results}

Given the average indoor radon concentration and building occupancy rates, the WISE Uranium Project calculator allows the calculation of dose rates for individuals exposed. The values used in these calculations are from the ICRP-65 [7]. Table 3 shows values for the radiation dose per hour and per year, and the health risk for an individual exposed to radon and its decay products assuming the minimum and maximum radon concentrations found in this survey, $37 \mathrm{~Bq} \cdot \mathrm{m}^{-3}$ and $179 \mathrm{~Bq} \cdot \mathrm{m}^{-3}$ respectively, and an $80 \%$ occupancy rate.

\section{Conclusions}

In general, the low average indoor radon concentrations found mean that indoor radon poses a low health risk in these areas.

An important purpose of this paper is to show that cli-

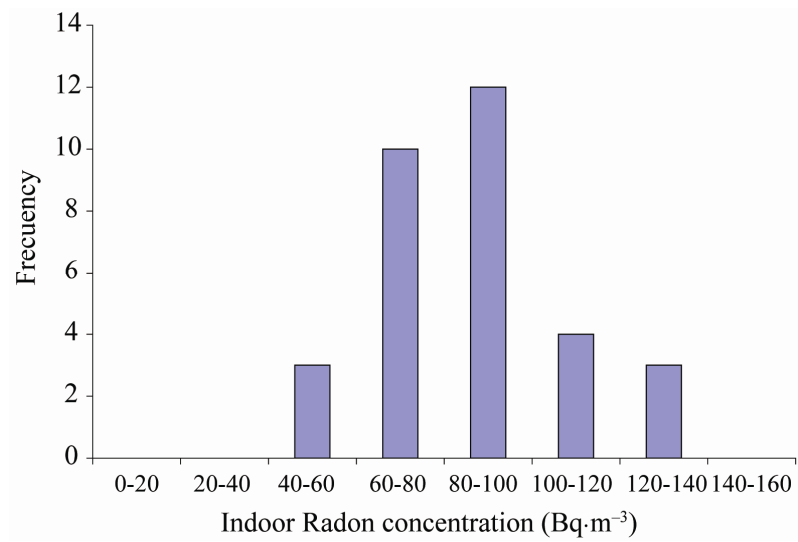

Figure 2. Frequency distribution of state mean indoor radon levels.

Table 3. Radiological risk assuming an $80 \%$ occupancy time per year.

\begin{tabular}{|c|c|c|}
\hline Radon concentration & $37 \mathrm{~Bq} / \mathrm{m}^{3}$ & $179 \mathrm{~Bq} / \mathrm{m}^{3}$ \\
\hline Dose (per hour) & $92.96 \mathrm{nSv} / \mathrm{h}$ & $449.7 \mathrm{nSv} / \mathrm{h}$ \\
\hline Dose (per year) & $\begin{array}{c}651.9 \mu \mathrm{Sv} / \mathrm{y} \\
(0.163 \mathrm{WLM} / \mathrm{y})\end{array}$ & $\begin{array}{c}3.153 \mathrm{mSv} / \mathrm{y} \\
(0.788 \mathrm{WLM} / \mathrm{y})\end{array}$ \\
\hline
\end{tabular}

mate and the associated ventilation habits are important parameters to consider in the context of indoor radon concentration surveys which include a large number of measurements and cover large geographical areas.

We hope that this experience can be of use to other researchers who seek to carry out surveys of indoor radon concentrations in other countries with climatologically and economic conditions similar to those of Mexico, and contribute to an extension of the coverage of indoor radon surveys at a worldwide level.

Finally, we conclude that indoor radon concentration levels do not change drastically over a period of ten years in the absence of dramatic changes in climatic or geographical conditions.

\section{Acknowledgements}

The authors wish to thank to J.I. Golzarri for his technical help. This work was partially supported by Oak Ridge National Laboratory (managed by UT-Battelle Corp.) and by PAPIIT-DGAPA-UNAM project 1N101910.

\section{REFERENCES}

[1] United States Scientific Committee on the Effects on Atomic Radiation (UNSCEAR), "Sources and Effects of Ionizing Radiation,” United Nations, New York, 2000.

[2] J. C. Miles, "Mapping Radon Prone Areas by Log-Normal Modeling of House Data," Health Physics, Vol. 74, No. 3, 1998, pp. 370-378. doi:10.1097/00004032-199803000-00010

[3] United States Environmental Protection Agency (USEPA), Environments Division (6609J), “A Citizen’s Guide to Radon: The Guide to Protecting Yourself and Your Family from Radon,” Washington DC 20460 US EPA 402-K-02-006, 2004.

[4] J. J. Whicker and M. W. McNaughton, "Work to Save Dose: Contrasting Effective Dose Rates from Radon Exposure in Workplaces and Residences against the Backdrop of Public and Occupational Regulatory Limits," Health Physics, Vol. 97, No. 3, 2009, pp. 248-256.

[5] World Health Organization (WHO), "Handbook on Indoor Radon, A Public Health Perspective,” 2009.

[6] International Atomic Energy Agency (IAEA), "Radiation Protection against Radon in Workplaces Other than Mines,” Safety Report Series, Vol. 33, 2003, pp. 11-12.

[7] International Commission on Radiological Protection (ICRP), "Protection against Radon-222 at Home and Work,” ICRP Publication 65, Pergamon Press, Oxford, 1994.

[8] N. Kavasi, T. Kovacs, C. Nemeth, T. Szabo, Z. Gorjanacs, A. Varhegyi, J. Hakl and J. Somlai, "Difficulties in Radon Measurements in Workplaces," Radiation Measurements, Vol. 41, No. 2, 2006, pp. 229-234. doi:10.1016/j.radmeas.2005.02.001 
[9] G. Akerblom, "Radon Legislation and National Guidelines Swedish Radiation Protection Institute,” SSI Report, 99-18, ISSN 0282-4434, 1999.

[10] G. Espinosa and R. B. Gammage, "Indoor Radon Concentration Survey in Mexico,” Journal of Radioanalytical and Nuclear Chemistry, Vol. 236, 1998, pp. 227-229. doi:10.1007/BF02386347

[11] G. Espinosa and R. B. Gammage, "Measurement Methodology for Indoor Radon Using Passive Track Detector," Applied Radiation and Isotopes, Vol. 44, No. 4, 1993, pp. 719-723. doi:10.1016/0969-8043(93)90138-Z

[12] G. Espinosa, J. I. Golzarri, J. Bogard, I. Gaso, G. Ponciano, M. Mena and N. Segovia, "Indoor Radon Measurements in Mexico City,” Radiation Measurements, Vol. 43, Suppl. 1, 2008, pp. 431-434. doi:10.1016/j.radmeas.2008.03.039

[13] R. B. Gammage and G. Espinosa, "Digital Image System for Track Measurements,” Radiation Measurements, Vol. 28, No. 1-6, 1997, pp. 835-838. doi:10.1016/S1350-4487(97)00193-5

[14] M. Walchuk, “Speaking up about Radon,” Health Physics News, Vol. XXXVIII, No. 4, 2010, pp. 1, 4-7.

[15] H. Arvela, H. Reisbacka and P. Keraenen, "Radon Prevention and Mitigation in Finland: Guidance and Practice," Proceedings of the American Association of Radon Scientists and Technologists 2008, Las Vegas NV, 14-17 September 2008.

[16] H. Friedmann, "Final Results of the Austrian Radon Project,” Health Physics, Vol. 89, 2005, pp. 339-348. 